\title{
Features and limitations of digital human models - a new German guideline
}

\author{
Gert Zülch ${ }^{\mathrm{a},{ }^{*}}$ \\ a ifab-Institute of Human and Industrial Engineering, Karlsruhe Institute of Technology (formerly University of \\ Karlsruhe), Kaiserstrasse 12, D-76131 Karlsruhe, Germany
}

\begin{abstract}
In 2008 the Association of German Engineers (VDI) published the first part of the VDI 4499 guideline for methods and tools for the digital factory. Part 1 of this guideline deals with the fundamentals of the system and will be expanded by the addition of further parts on specific topics within the digital factory. Soon to be published is Part 4 which covers human models as tools of the digital factory. It describes the state of the art of current digital human models with regards to the methods and procedures implemented in German speaking countries. The structure of this part of the guideline is based on the different sections of engineering mechanics and outlines the opportunities for ergonomic assessments and the evaluation of work systems. During the writing of the guideline, the restrictions of the existing procedures also became evident thus showing the requirement for further development of such procedures. This is illustrated in this paper using examples from commercial software systems.
\end{abstract}

Keywords: human modelling, digital factory, ergonomic evaluation, anthropometry, prospective work design

\section{Human models in the digital factory}

Digital human models are already an essential tool in the planning of new production plants. These models serve to represent defined groups of people with the highest level of anthropometrical precision as well as to assess and evaluate future work processes and systems for a prospective work design. The objective is to forecast future stress and strain on manpower and the risks on occupational health and safety in order to determine remedial measures in a suitable timeframe and to present ways to facilitate the work. There are various levels of detail, from the visualisation of complete macro work systems to ergonomic assessments and time management evaluations of individual micro work systems (Figure 1).

Commercial software systems available for digital factory planning utilise a joint data basis for the development and production of a future product including all the production processes and systems. Moreover, commercial software systems deliver the data for designing the production processes and systems within the product life cycle. As well as the commercially available solutions there are also scientific procedures which have been developed specifically for certain types of visualisation and assessment,

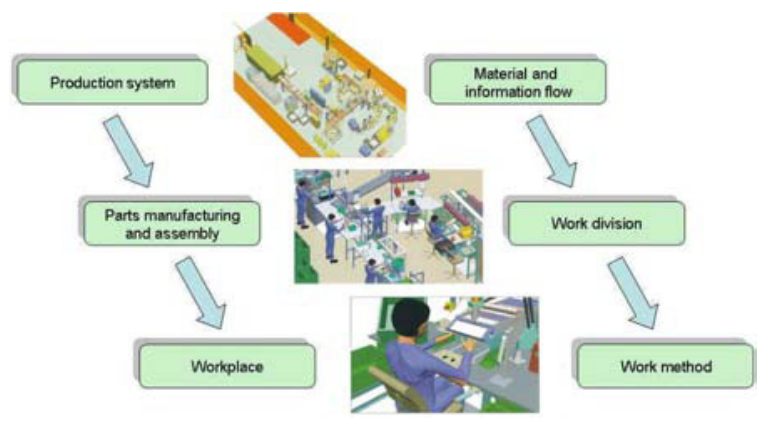

Fig. 1: Levels of detail in work systems planning using digital human models (Software graphics: Dassault Systèmes 2004)

but which have not been integrated into the more extensive tools for digital factory planning.

Since the beginning of 2007 a working group of the Association of German Engineers (VDI) has been collaborating on a new part of the guideline which is aimed at detailing the current status of human model-

\footnotetext{
* Corresponding author. Phone: ++49-721-608-44839, Fax: ++49-721-608-47935, E-mail: gert.zuelch@kit.edu..
} 
ling procedures available within the digital factory tools. The group intends to document the results within VDI Guideline 4499 "Digitale Fabrik" (Digital factory) and to publish them in Part 4 of this guideline titled "Abbildung des Menschen in der Digitalen Fabrik" (Representation of human resources in the digital factory) [40]. In 2008 the VDI published Part 1 of this guideline under the title "Grundlagen" (Fundamentals) [39], which outlines both the definitions and the application field of digital factory tools.

The new part of this guideline will focus on the aspects of anthropometrics and occupational physiology of human models, which result from a specific future job or task. The scope of application is process ergonomics, specifically within assembly areas. Therefore, applications for product ergonomics, specifically vehicle ergonomics, will not be detailed in this paper although many new developments originate from within this area. Additional aspects such as the assessment and evaluation of environmental influences on the work system will probably be discussed in a separate part at a later date.

The human modelling procedures discussed within this part of the guideline focus mainly on geometric human modelling. Some procedures enable the animation of the human model which can display work processes ranging from some seconds to a few minutes. Personnel-based simulation procedures, as outlined in the VDI Guideline 3633, Part 6 [38], are concerned with longer periods of time from some minutes to a few months. These particular procedures do not offer three-dimensional human models but focus on business graphs, illustrations of Gantt charts and waiting queues etc.

\section{Analysing and assessing human models}

Using a more engineering-based approach, the new guidelines cover the functionalities of human modelling procedures available within Germanspeaking countries by focusing on engineering mechanics. From this perspective the anthropometric aspects of human modelling can be divided into geometry and kinetics. The aspect of occupational physiology can be divided into statistics and dynamics (Figure 2).

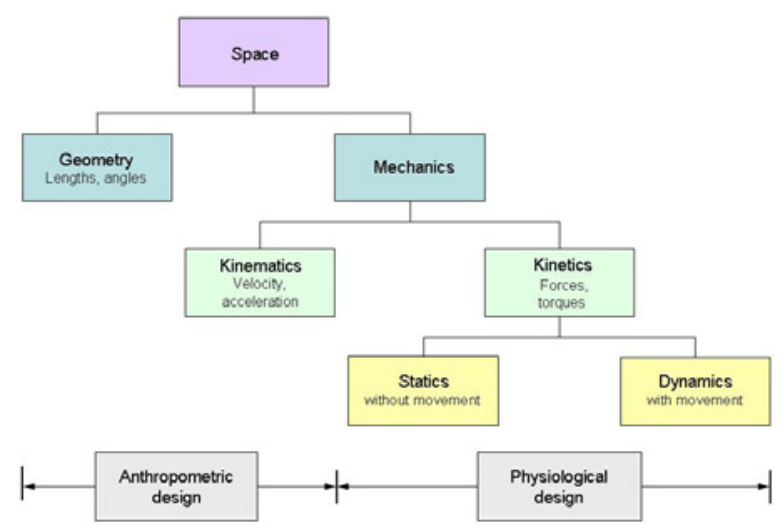

Fig. 2: Areas of engineering mechanics and ergonomic workplace design (following [47], p. 110)

\subsection{Geometry}

The purpose of a geometrical analysis conducted as part of a prospective work place design is to show the interaction between objects within the work system, and the digital representative of a group of people to which a specific job or role is be assigned. When using the digital factory tools, the work object is usually a CAD model, however many of the databases include information which is not required for the digital design of a work system. It is for this reason, that data reduction methods are necessary to reduce the amount of computing required. Data reduction methods are also required for modelling both the work place and the working area. Very often simplified model data of equipment and furniture is sufficient. This can be stored in catalogues where data can be parameterised, if required.

Geometric human modelling focuses on presenting the dimensions and angle positions of human limbs as realistically as possible. Digital human models which are used for vehicle ergonomics are very accurate and demonstrate these aspects clearly (e.g. see [4, 15]). Figure 3 shows an example for human spine modelling as well as the specification of seat reference points which are required mainly for ergonomic vehicle interior design.

Presenting both human models and the required equipment and furniture in the work area is a method which is highly suited to demonstrating the future design of a work system (Figure 4). This will lead to easier discussions with stakeholders that may be less familiar with two-dimensional layout plans. However, collisions between the human models and furniture and work-related items can only be demonstrated 
visually and then solved through restructuring the work system. Such collisions may not yet be recognised or solved with software calculations.

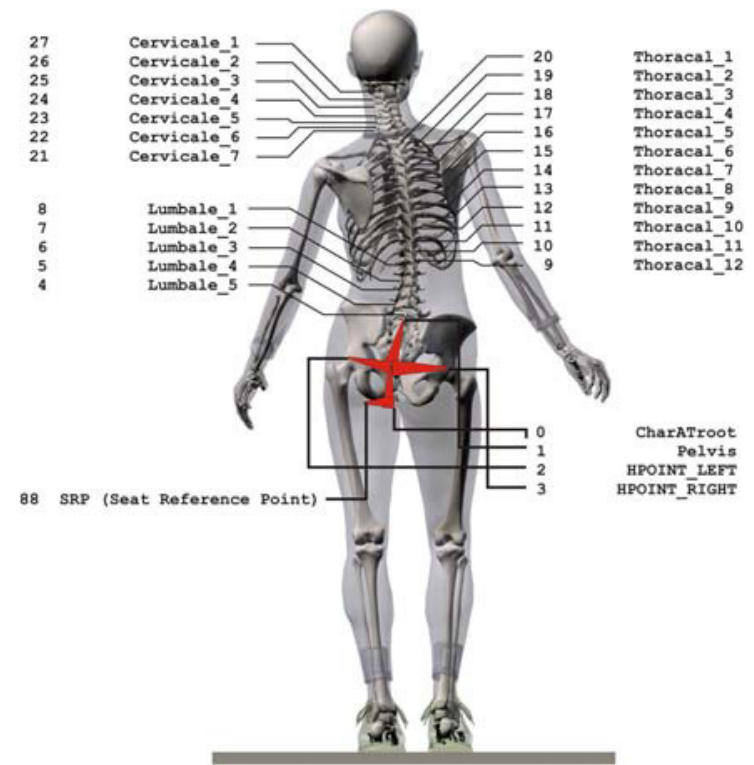

Fig. 3: Spine and seat reference points modelled with CharAT Ergonomics [42]

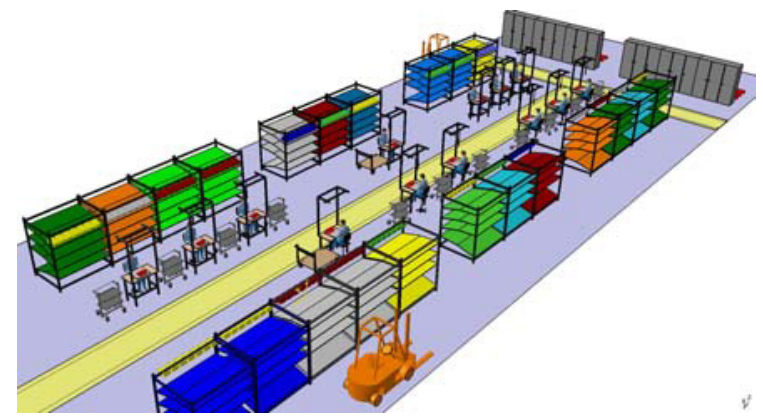

Fig. 4: Visualisation of an assembly system (Software graphics: Dassault Systemes)

Human models usually represent the 5th, 50th and 95th percentile for male and female distributions. Differing ethnic groups can often be represented as well. Some procedures also allow for the illustration of specific somatotypes or even individual persons. However, the calculation of spatial deformations of the body due to surface pressure and motion is still in its initial stages (see [24]).

In addition to the dimension and the angle of limbs, the operating space of the human body can be represented in the digital models, specifically the required radius for grasping items and the field of view. These illustrations are typically based on simplified geometries, which are sufficient for a primary assessment (see [12]).

The illustration of human joints poses a specific challenge. Although simplified modelling of the spine based upon the assumption of a fictitious neckchest- or lumbar joint is seen as outdated, human joints are generally approximated by using simple hinge joints.

The anatomically accurate modeling as a spatial track joints is still in its preliminary research phase [9, 23]. The same applies to the modelling of reach envelopes or the field view. Often research focuses on accessibility and visibility; it is only recently that questions regarding comfort have been investigated as part of research projects $[14,18]$. It is within this context that research will have to clarify whether the assumed neutral body posture taken from aerospace research and detailed in NASA-Standard 3000 [25, p. 3-57]) can be regarded as a comfortable position at normal gravitational forces.

\subsection{Kinematics}

The presentation of the required radius for grasping and the field of view leads to the kinematic analysis. In addition to dimensions and angles within the human body's range of motion, the kinematic analysis covers both velocity and acceleration of the limbs as well as eye movement in the forms of saccades and eye fixations.

When generating motion through human joint chains, it must be clarified whether the angle change should be reduced in total for all joints or in the maximum value of one individual joint (see inverse kinematics, e.g. [45], pp. 155).

Usually pre-determined time systems are used for the time evaluation of motion; the MTM methodology $[11,20]$ is used almost exclusively for this purpose at each of the varying levels of detail. Figure 5 shows the Gantt chart for handling a work object.

Various research projects (e.g. [21]) have shown that the required time to reach an object is not only dependent on the distance (and the conditions for reaching) but also on both the starting point, and the end point of the motion in relation to the respective horizontal body plane. The number of assumed cases of mobility restrictions should be increased, specifically with regards to the use of personal protective clothing and their impact on mobility restrictions. 




Fig. 5: Gantt chart and visualisation of handling a work object [31]

Procedures using pre-determined time systems are usually based on the use of experienced persons with normal skills. This however requires further clarification. It should be investigated whether gender-specific differences must also be considered (e.g. for fine motor movements). Recently and as part of demographic change, the question of age-specific differences in motion times has emerged. This question also requires further research work.

\subsection{Statics}

In addition to the anthropometric study, it is essential to evaluate human models from the perspective of occupational physiology. Existing human modelling procedures are usually limited to the analysis of static posture and static work. The neutral body posture excluding the effect of external forces can be evaluated and assessed using either the Finish OWAS method [37], the American NIOSH method [43] or the NASA standard STD 3000 [25]. The first two methods mentioned have been used in the "Process Simulate" procedure [29, 31], the latter method has been used in the IDO:ErgonomiX procedure [16]. All three methods also consider external factors thus allowing for assessment of both static posture and static work.

Figure 6 shows an example of a static work assessment with the Process Simulate procedure [31]. When using this procedure, the user has to identify the critical situation of load handling which usually occurs when commencing or completing a work operation. The assessment can be performed using either the American methods NIOSH [43] and 3D SSPP [8] or the British method RULA [22].

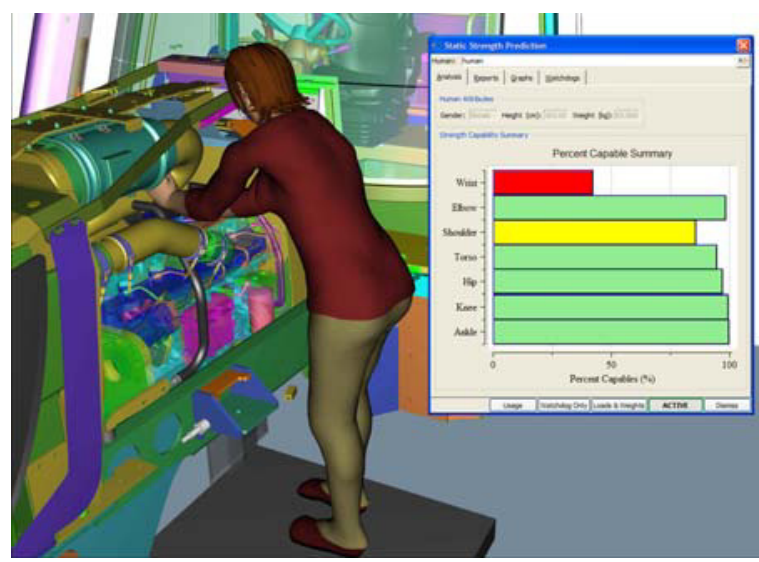

Fig. 6: Posture analysis using the 3D SSPP method $[7,8,31]$

The VDI method which is often been used for assessments in Germany [5, pp. 223; 28, pp. 70; 41, pp. 48] is available in the EKIDES procedure [19]; assessment according to the NIOSH method [43] is also available. The Load Calculator for Lifting and Carrying (HuT; [2]) offers calculations following the the German Standard DIN EN 1005-4 [10] , the Key Indicator Method (LM; [35]) and the NIOSH method as well. These methods can be used to specify the admissible upper load limits but they use different influencing variables. The NIOSH method only focuses on the load resulting from a specific task while the VDI method also considers personnel factors. As a consequence, these procedures may deliver differing results. The Key Indicator Method, published by the German Federal Agency of Occupational Safety and Health (BAuA) in an online form [3], can also lead to different results in its final assessment (Figure 7; see also [47]).

Neither the VDI method nor the LM method have been integrated into the available tools of the digital factory, they can only be used as individual tools thus meaning that data needs be entered separately. It can be seen that Anglo-American assessment methods are dominant in international commercial humanmodelling procedures whereas procedures developed in Germany are usually not integrated into the software systems for digital factory planning.

The tools available in the digital factory are not capable of calculating collisions between the human body and other objects. It is for this reason that the static balance can only be assessed from a visual point of view. This applies specifically to supportpoints, where the human body or parts thereof rest on objects of the work system. 


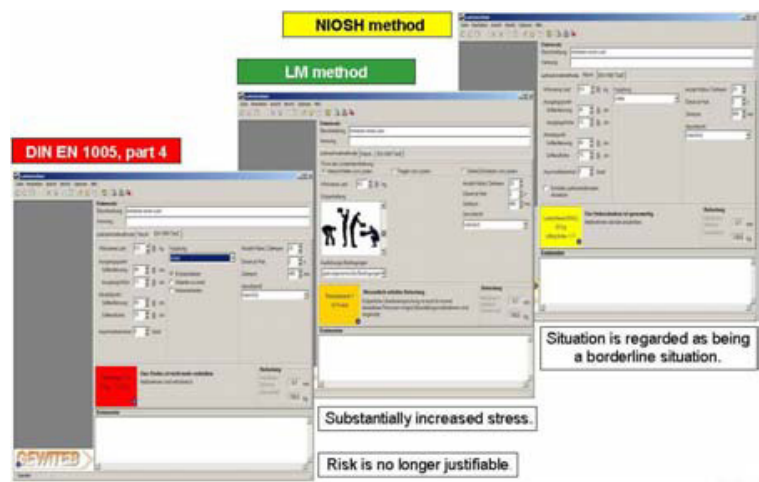

Fig. 7: Assessment of the same load-lifting situation with different methods using the Load Calculator HuT (Software graphics: ASER [2])

\subsection{Dynamics}

The methods according to VDI, NIOSH and BAuA consider the frequency of load handling in their assessment and are thus leading to a dynamic analysis of work processes. However, only the load handling phases of the job is included in the evaluation and assessment while all other work operations that occur during work hours are not considered.

To assess dynamic work, in addition, the metabolic energy consumption can be analysed. This method goes back to Spitzer et al. [34] and is available in the ergonomic analysis procedure EKIDIS [19]. The human model JACK in the "Process Simulate" procedure Fout! Verwijzingsbron niet gevonden. uses an American method [13] to analyse the metabolic energy consumption, or to be more correct, it uses the EEPP software (Energy Expenditure Prediction Program [7]) based on this method. This procedure also includes a method for calculating the recovery time which is based on the research work by Rohmert ([24]; see also [26], pp. 136).

Apart from these well-known procedures for a global assessment of dynamic muscular activity, dynamic analysis for human modelling is in its infancy (see [45] for the theory behind it). There are procedures available from the field of biomechanics but they are not integrated into the procedures of the digital factory. These procedures include for example the German procedure DYNAMICUS [17] and the Danish procedure AnyBody [1]. Figure 8 shows an anatomical human model for operating a pedal. The analysis shows the resulting muscle activity in relation to the seating position and the spring-stiffness of the pedal.
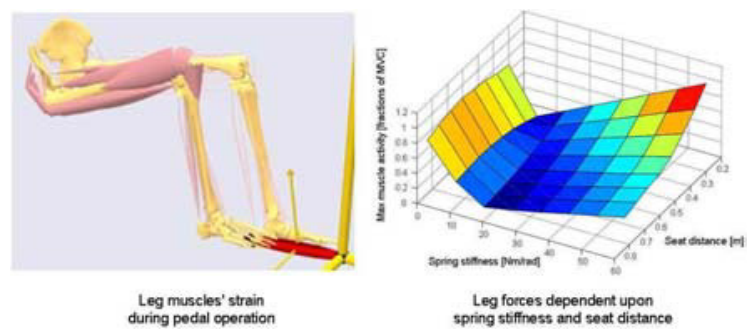

Fig. 8: Leg forces acting on a pedal (Software graphics: Anybody [1])

Further impetus for dynamic analysis can be expected from the field of multi-body mechanics. Essential research is currently being conducted on developing humanoid robots. It investigates the question of how human limb motion or the motion of limb chains can be animated based on the end point of the motion and considering the posture, orientation and mass of human limbs. If these motions was investigated and clarified, the patterns could be transferred to the movements of humanoid robots. Currently it is still unclear, however, whether the deflection of human joints should be minimised in their average value or maximum value or whether the initial change rate of acceleration (i.e. the jerk) is essential and should thus be generated (MKD-Tools; [32, 36].

\section{Limitations and future developments}

The explanations outlined in this paper were not only intended to reflect the current state of the art of human modelling within the digital factory. It was also intended that they show the limitations of current human modelling procedures and thus the requirements for further development (see [33]). In addition to the aspects mentioned, any further development should focus on the options for collision recognition, collision avoidance and the calculation of static balance conditions as well as end point motion generation from the perspective of human kinematics and dynamics. These last requirements go beyond the virtualisation of motion paths that are tracked with motography (e.g. $[18,30])$.

One of the main challenges is that the dominating position of internationally available commercial procedures within the digital factory can lead to a situation where evaluation and assessment methods developed in Germany are not being integrated in the digital factory. In order to ensure the integration of 
such methods, the requirements for these methods must be clarified, so they can be integrated into the model environment of commercial procedures.

Another aspect which is usually neglected is the consideration of environmental effects in the evaluation and assessment of digital work systems [46]. Stress and strain models should not only be restricted to the work task, they should also consider the work environment. The tools available in the digital factory currently do not offer such an approach. It is for this reason that an additional part of the VDI 4499 guideline documenting the current state of the art and outlining ideas for further development is urgently required.

\section{References}

[1] AnyBody Technology (ed.), Occupational Health, Anybody Technology A/S, Aalborg, 2009. http:// www.anybodytech.com/index.php?id=162, accessed: 18.07.2011.

[2] ASER - Institut für Arbeitsmedizin, Sicherheitstechnik und Ergonomie (ed.), Der Heben und Tragen Rechner, 2008. http://www.institut-aser.de/out.php?idart $=538, \quad$ accessed: 12.08.2011.

[3] BAuA - Bundesanstalt für Arbeitsschutz und Arbeitsmedizin (ed.), Gefährdungsbeurteilung mithilfe der Leitmerkmalmethode, 2009. http://www.baua.de/de/Themen-von-A-Z/ Physische-Belastung/Gefaehrdungsbeurteilung.html ? nnn=true, accessed: 08.01.2010.

[4] H. Bubb, F. Engstler, F. Fritzsche, Ch. Mergl, O. Sabbah, P. Schaefer, P. and I. Zacher, The development of RAMSIS in past and future as an example for the cooperation between industry and university, International Journal of Human Factors Modelling and Simulation, 1:1 (2006), 140-157.

[5] H.-J. Bullinger, Ergonomie, Teubner, Stuttgart, 1994. (Technologiemanagement)

[6] Center for Ergonomics (ed.), 3D SSPP Example Application, 2011, University of Michigan, Ann Arbor, MI. http://www.engin.umich.edu/dept/ioe/3DSSPP/example.html, accessed: 28.05.2011.

[7] Center for Ergonomics (ed.), Energy Expenditure Prediction Program, 2004, University of Michigan, College of Engineering, Ann Arbor, MI. http://www.engin.umich.edu/dept/ ioe/ENGEXP/index.html, accessed: 18.07.2011.

[8] D. B. Chaffin, Development of Computerized Human Static Strength Simulation Model for Job Design, Human Factors and Ergonomics in Manufacturing, 7:4 (1997), 305-322.

[9] C. Charbonnier, J. Schmid, F. Kolo-Christophe, N. MagnenatThalmann, C. Becker and P. Hoffmeyer, P, 2009, Virtual Hip Joint: from Computer Graphics to Computer-Assisted Diagnosis, in: Eurographics 2009 - First Medical Prize, K. Bühler and D. Bartz, eds., Eurographics Association, München, 2009, pp. 1-4. http://www.miralab.unige.ch/repository/papers/508.pdf; accessed: 11.01.2010.

[10]Din En 1005-4: 2009-01, Safety of machinery - Human physical performance - Part 4: Evaluation of working postures and movements in relation to machinery, German version EN 1005-4:2005+A1:2008. Beuth, Berlin.

[11] Deutsche MTM-Vereinigung (ed.), TiCon-Module Base 2010, Deutsche MTM-Vereinigung. Hamburg. https://www.dmtm.com/produkte/software/ticon_modul_base. php, accessed: 19.07.2011.

[12]J. Firemanand N. Lesinski, Virtual Ergonomics: Taking Human Factors into Account for Improved Product and Process, 2009, Dassault Systèmes Delmia, Auburn Hills, MI. http://www.3ds.com/de/products/delmia/solutions/humanmodeling/overview/\#vid1 Virtual Ergonomics Whitepaper, accessed: 11.01.2010.

[13]A. Garg, D. B. Chaffin, G. D. Herrin, Prediction of metabolic rates for manual materials handling jobs. American Industrial Hygiene Association Journal, 39:12 (1978), 661-674.

[14]J. Hudelmaier, Das Menschmodell RAMSIS, 2010. http://www.lfe.mw.tu-muenchen.de/forschung/ humanmodeling/Ramsis_Flyer.pdf, accessed: 08.01.2010.

[15]Human Solutions (ed.), Mehr Ergonomie im Fahrzeug, Human Solutions, Kaiserslautern, 2010. http://www.humansolutions.com/automotive/products de.php, accessed: 08.01 .2010

[16]ICIDO (ed.), Ido:Ergonomics, ICIDO GmbH, Stuttgart, 2008. http://www.icido.de/de/Produkte/VDP/IDO_Ergonomics.html, accessed: 08.01.2010.

[17]IFM (ed.), Anwendungsbeispiele des biomechanischen Menschmodells DYNAMICUS, Institut für Mechatronik an der TU Chemnitz, Chemnitz, 2010. http://www.tu-chemnitz.de/ifm/produkte-html/DYNAMICUS_Anwendungen.html, accessed: 08.01.2010.

[18]INRETS-LBMC (ed.), Digital human modeling for ergonomic simulation, Biomechanical evaluation of discomfort, Bron Cédex 2010. http://www.inrets.fr/ur/lbmc/english/Ergo/ IndexTheme.html, accessed: 08.01.2010.

[19]I. Jastrzebska-Fraczek and H. Schmidtke, EKIDES 9.07 - ein zweisprachiges Tool für die Unterstützung des Gestaltungsprozesses und Steigerung der Qualität der Produkte und Arbeitsplätze, Lehrstuhl für Ergonomie der TU München, München, 2010. http://www.lfe.mw.tumuenchen.de/index3.htm $\sim$ EKIDES..., accessed: 08.01.2010.

[20]D. Karger, W. Bayha and H. Franklin, Engineered Work Measurement. Industrial Press, New York, NY, 4th ed. 1987.

[21]K. Kluth, J. Böhlemann and H. Strasser, Beanspruchung des Hand-Arm-Schulter-Systems in Abhängigkeit von Arbeitsgeschwindigkeit, Arbeitsfeld und Umlaufrichtung, in: Beanspruchungsgerechte Planung und Gestaltung manueller Tätigkeiten, H. Strasser, ed., ecomed Verlagsgesellschaft, Landsberg/Lech, 1996, pp. 83-110.

[22]L. McAtamney and E. N. Corlett, RULA: A survey method for the investigation of work related upper limb disorders, Applied Ergonomics, 24 (1993), 91-99.

[23] MIRALab (ed.), Medical, 2010, University of Geneva, MIRALab, Geneva. http://www.miralab.unige.ch/ 3D medical simulation, accessed: 08.01.2010.

[24]MIRALab (ed.), Welcome to Miralab, 2010, University of Geneva, MIRALab, Geneva. http://miralab.unige.ch/ Media Gallery $\sim$ Modelling techniques $\sim$ Images, accessed: 18.07.2011.

[25]NASA - National Aeronautics and Space Administration (ed.) Man-systems integration Standards, NASA-STD-3000 Volume I, Revision B, Marshal Space Flight Center, Huntsville, AL, 1995. http://standards.nasa.gov/documents/detail/ 3314902, accessed: 11.01.2010.

[26]W. Rohmert and W. Laurig, Physische Beanspruchung durch muskuläre Belastung, 1993, in: Ergonomie, H. Schmidtke, ed., Hanser, München, Wien, 3rd ed., pp. 121-160.

[27]W. Rohmert, Physiologische Grundlagen der Erholungszeitbestimmung, Arbeit und Leistung, 19 (1965), 1-7.

[28]W. Schultetus, Montagegestaltung, Verlag TÜV Rheinland, Köln, 1980.(Praxis der Ergonomie) 
[29] Siemens PLM Software (ed.), Process Simulate, Plano, TX: Siemens PLM Software, 2009. http://www.plm. automation.siemens.com/de_de/products/tecnomatix/ assembly_planning/process_simulate/index.shtml, accessed: 30.12.2009.

[30] Siemens PLM Software (ed.), Jack and Process Simulate Human, 2010, Siemens PLM Software, Plano, TX. http://www.plm.automation.siemens.com/en_us/products/ tecnomatix/assembly_planning/jack/index.shtml, accessed: 08.01.2010.

[31] Siemens PLM Software (ed.): Process Simulate, 2011, Siemens PLM Software, Plano, TX: http://www.plm.automation.siemens.com/en_us/products tecnomatix/assembly_planning/process_simulate/index.shtml, accessed: 28.05.2011

[32] C. Simonidis, T. Stein, A. Fischer, F. Bauer, H. Schwameder and W. Seemann, MKD-Tools: Ein Mehrkörperalgorithmus zur Analyse und Synthese menschlicher Bewegungen, in: Biomechanik - Grundlagenforschung und Anwendung (Abstractband zur Tagung der dvs-Sektion Biomechanik), Universität Tübingen, Institut für Sportwissenschaft, Tübingen, 2009, pp. 42-44.

[33]B. Spanner-Ulmer and J. Mühlstedt, J., Virtuelle Ergonomie mittels digitaler Menschmodelle und anderer Softwarewerkzeuge, in: Digital Engineering - Herausforderung für die Arbeits- und Betriebsorganisation, M. Schenk, ed., GITOVerlag für Industrielle Informationstechnik und Organisation, Berlin, 2009, pp. 151-170. (Schriftenreihe der Hochschulgruppe für Arbeits- und Betriebsorganisation, HAB)

[34]H. Spitzer, Th. Hettinger and G. Kaminsky, Tafeln für den Energieumsatz bei körperlicher Arbeit, Beuth Verlag, Berlin, Köln, 6th ed., 1982.

[35]U. Steinberg, G. Caffier, D. Mohr, F. Liebers, and S. Behrendt, Modellhafte Erprobung des Leitfadens Sicherheit und Gesundheitsschutz bei der manuellen Handhabung von Lasten, Wirtschaftsverlag NW Verlag für neue Wissenschaft, Bremerhaven, 1998. (Schriftenreihe der Bundesanstalt für Arbeitsschutz und Arbeitsmedizin; Forschungsbericht Fb 804)

[36] G. Stelzner, Zur Modellierung und Simulation biomechanischer Mehrkörpersysteme, Universitätsverlag Karlsruhe,
Karlsruhe, 2009. (Schriftenreihe des Instituts für Technische Mechanik, Bd. 11)

[37] G. Stoffert, Analyse und Einstufung von Körperhaltungen bei der Arbeit nach der OWAS-Methode, Zeitschrift für Arbeitswissenschaft, 39 (1985), 31-38.

[38] VDI 3633, Blatt 6, Simulation von Logistik-, Materialflussund Produktionssystemen - Abbildung des Personals in Simulationsmodellen, edition 2001-10.

[39] VDI 4499, Blatt 1: Digitale Fabrik - Grundlagen, edition 2008-02.

[40] VDI 4499, Blatt 4: Digitale Fabrik - Abbildung des Menschen in der Digitalen Fabrik, draft 2011-07.

[41] VDI-Gesellschaft Produktionstechnik (ADB) (ed.), Handbuch der Arbeitsgestaltung und Arbeitsorganisation, VDI-Verlag, Düsseldorf, 1980.

[42] Virtual Human Engineering (ed.), CharAT Ergonomics, Virtual Human Engineering $\mathrm{GmbH}$, Stuttgart, w/o year. http://www. Virtualhumanengineering.com/index.php? option $=$ com_content\&view $=$ article\&id=12\&Itemid=16\&lang $=$ en, accessed: 28.05 .2011 .

[43] T. R. Waters, V. Putz-Anderson, A. Garg and L. J. Fine, Revised NIOSH equation for the design and evaluation of manual lifting tasks, Ergonomics, 36:7 (1993), 749-776.

[44] V. M. Zatsiorsky, Kinematics of Human Motion, Human Kinetics, Champaign, IL, 1998.

[45] V. M. Zatsiorsky, Kinetics of Human Motion, Human Kinetics, Champaign, IL, 2002.

[46]G. Zülch, Arbeitsschutz zwischen Umsetzungsdrang und Forschungsbedarf, in: Arbeitsschutz-Managementsysteme, G. Zülch and B. Brinkmeier, eds., Shaker, Aachen, 2000, pp. 185-201.

[47]G. Zülch, Perspektiven der Menschmodellierung als Werkzeug der digitalen Fabrikplanung, in: Digital Engineering Herausforderung für die Arbeits- und Betriebsorganisation, M. Schenk, ed., GITO-Verlag für Industrielle Informationstechnik und Organisation, Berlin, 2009, pp. 105-124. (Schriftenreihe der Hochschulgruppe für Arbeits- und Betriebsorganisation, HAB) 